\title{
ANALISIS KINERJA KOMBINASI SISTEM CODE DIVISION MULTIPLE ACCESS MULTIPLE INPUT MULTIPLE OUTPUT DENGAN KODE PENEBAR WALSH PADA KANAL RAYLEIGH FADING
}

\author{
I Gd. Tri Dharma Prawira ${ }^{1}$, I.G.A.K.Diafari Djuni Hartawan ${ }^{2}$, N. Pramaita ${ }^{3}$ \\ ${ }^{123}$ Program Studi Teknik Elektro, Fakultas Teknik, Universitas Udayana \\ Email: triidharma@gmail.com ${ }^{\underline{1}}$, igak.diafari@ee.unud.ac.id ${ }^{2}$, pramaita@ee.unud.ac.id ${ }^{\underline{3}}$
}

\begin{abstract}
ABSTRAK
Meningkatnya populasi manusia berbanding lurus dengan kebutuhan akan telekomunikasi. Code Division Multiple Acess (CDMA) merupakan salah satu teknologi telekomunikasi yang banyak digunakan. Namun dengan meningkatnya jumlah pengguna, teknologi ini tidak lagi mampu memenuhi kebutuhan dari pengguna. Dengan kebutuhan kapasitas yang diperlukan, maka dilakukan penggabungan sistem CDMA dan teknologi Multiple Input Multiple Output (MIMO).

Untuk mengetahui unjuk kerja sistem gabungan CDMA MIMO, sistem diuji dengan kondisi pertambahan jumlah user dan Signal to Noise Ratio (SNR) dimana kode penebar yang digunakan adalah kode Walsh dan kanal yang digunakan adalah pemodelan Rayleigh Fading. Nilai acuan yang digunakan sebagai bahan pertimbangan adalah nilai Bit Error Rate (BER).

Metode yang digunakan dalam pengujian sistem CDMA MIMO adalah pertambahan jumlah user, dimulai dengan single user sampai dengan 16 users serta nilai SNR dari -15 dB sampai maksimal $15 \mathrm{~dB}$. Dimana seluruh user akan digabungkan dengan teknik CDMA kemudian akan dikirimkan dengan menggunakan teknologi MIMO. Sistem akan diuji menggunakan simulasi dari software MatLab R2012a.

Hasil dari simulasi menunjukkan kinerja sistem CDMA MIMO pada saat menggunakan SNR yang bertambah tinggi, BER akan semakin rendah atau semakin baik digunakan untuk melakukan komunikasi. Sedangkan untuk simulasi menggunakan user yang bertambah menghasilkan nilai BER yang hampir sama karena sifat dari kode walsh yang orthogonal sehingga setiap user tidak mengalami inteferensi dengan user lainya.
\end{abstract}

Kata Kunci: MIMO, CDMA, BER, SNR

\section{ABSTRACT}

The increasing human population are same to the need for telecommunications. Code Division Multiple Access (CDMA) is one of the most widely used telecommunications technologies. But with the increasing number of users, this technology is no longer able to meet the needs of users. With the required capacity requirements, the CDMA system and Multiple Input Multiple Output (MIMO) technology are merged.

To find out the performance of a combined CDMA MIMO system, the system was tested by increasing the number of users and Signal to Noise Ratio (SNR) where the spreading code used was the Walsh code and the channel used was Rayleigh Fading modeling. The reference value used as material for consideration are the value of Bit Error Rate (BER).

The method used in testing the CDMA MIMO system is the increase number of users, starting with a single user up to 16 users and SNR values from -15 dB to a maximum of $15 \mathrm{~dB}$. 
Where all users will be combined with the CDMA technique then it will be sent using MIMO technology. The system will be tested using a simulation of the MatLab R2012a software.

The results of the simulation show the performance of the CDMA MIMO system when using SNR that is increasing high, the BER will be lower or better used for communication. Whereas for simulations using a user that increases it results in a BER value that is almost the same because of the nature of the orthogonal Walsh code so that each user does not experience interference with other users.

Keyword: MIMO, CDMA, BER, SNR

\section{PENDAHULUAN}

Teknologi komunikasi seluler merupakan teknologi yang paling pesat perkembangannya dibandingkan dengan teknologi komunikasi lainnya. Kebutuhan akan komunikasi yang terus berkembang, mengakibatkan meningkatnya permintaan pelayanan yang diberikan dalam teknologi komunikasi seluler.

Telah terjadi berbagai perkembangan teknik komunikasi seluler dalam beberapa dekade ini. Dimulai dari teknologi komunikasi seluler pertama (1G), yang kemudian dikembangkan hingga kini menjadi generasi keempat (4G). Pada generasi kedua (2G), salah satu teknologi yang diterapkan oleh penyedia layanan komunikasi seluler adalah teknologi CDMA. CDMA (Code Division Multiple Acess) merupakan suatu sistem akses jamak yang digunakan untuk mengirimkan beberapa informasi secara bersamaan dengan menggunakan frekuensi yang sama untuk berbagai user dan menggunakan korelasi kode untuk membedakan user satu dengan user lainnya

Seiring perkembangan teknologi, CDMA yang masih menggunakan single antenna memiliki masalah terhadap kapasitas yang mampu diberikan oleh sebuah single antenna. Demi memenuhi kebutuhan dari user muncullah sebuah metode yang disebut dengan Multiple Input Multiple Output (MIMO). MIMO merupakan sebuah metode dimana jumlah antenna yang digunakan sebagai pemancar dan penerima lebih dari satu buah antena. Dengan demikian, teknologi MIMO memberikan kapasitas yang lebih besar dibandingkan dengan menggunakan sebuah antena pemancar dan sebuah antena penerima [1].

\section{KAJIAN PUSTAKA}

2.1 Sistem Code Division Multiple Access Code Division Multiple Access (CDMA), Gambar 1, merupakan suatu bentuk pemultipleksan dan sebuah metode akses jamak yang setiap kanalnya menggunakan periode waktu dan frekuensi secara bersamaan. Untuk membedakan setiap pengguna maka digunakan kode unik. Selain sebagai pembeda, kode unik juga digunakan untuk melebarkan sinyal. Kode ini disebut dengan Pseudo Random Noise (PN Code) [2].

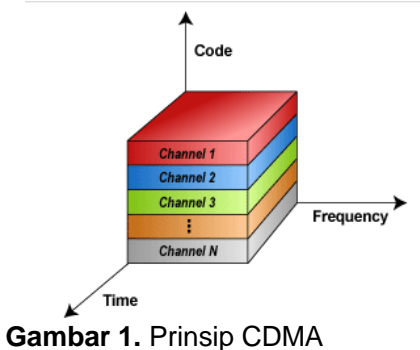

\subsection{Kode Walsh-Hadamard}

Kode Walsh Hadamard merupakan kode orthogonal yang digunakan untuk memisahkan kanal-kanal sistem CDMA. Sebuah simbol Walsh adalah sebuah baris atau kolom yang ada pada hadamard matrik. Setiap simbol Walsh terdiri atas chip-chip Walsh. Karena matriks Hadamard berukuran $M \times M$, yaitu $M=2^{a}$, dengan a panjang data input Walsh, maka setiap simbol Walsh memiliki panjang $\mathrm{M}$ bit dan total simbol Walsh dalam matrik Hadamard adalah 
sebanyak M simbol [3]. Karakteristik matriks Hadamard adalah antar baris atau antar kolom saling orthogonal. Dengan kata lain korelasi antar baris atau antar kolom menghasilkan nilai sama dengan nol. Hal tersebut dapat di jelaskan sebagai berikut

$$
H_{4}=\left[\begin{array}{rrrr}
1 & 1 & 1 & 1 \\
1 & -1 & 1 & -1 \\
1 & 1 & -1 & -1 \\
1 & -1 & -1 & 1
\end{array}\right]
$$

Dalam hal ini diambil elemen-elemen yang ada pada baris 2 dan baris 3 . Melalui perhitungan berikut dapat dilihat bahwa baris 2 dan 3 saling orthogonal.

$1 \times 1+-1 \times 1+1 x-1+-1 x-1=1+(-1)+(-1)+1=0 \ldots$

Dari perhitungan di atas dapat dilihat bahwa perkalian antar elemen yang bersesuaian (baris yang berbeda tetapi kolom yang sama) menghasilkan nilai 0 . Korelasi antar pasangan baris berbeda menghasilkan nilai 0. Hal ini menunjukkan bahwa antar baris berbeda pada matriks Hadamard adalah saling orthogonal [3].

\subsection{Multiple Input Multiple Output (MIMO)}

Suatu sistem Multiple Input Multiple Output (MIMO) merupakan suatu sistem wireless yang dilengkapi dengan $\mathrm{N}_{T}$ antena di sisi transmitter dan $\mathrm{N}_{\mathrm{R}}$ antena di sisi receiver, diilustrasikan pada Gambar 2 . Setiap antena transmitter akan mengirimkan informasi yang berbeda satu dengan yang lain. Ide dasar dalam sistem ini adalah untuk memanfaatkan efek multipath fading, yang merupakan pengganjal, biasa terjadi dan seringkali mengganggu dalam komunikasi wireless.

Prinsip kerja dari MIMO adalah dengan memperbanyak sinyal informasi yang dikirimkan untuk meningkatkan kemampuan komunikasi dengan mengurangi error yang dapat terjadi karena proses transmisi [4].

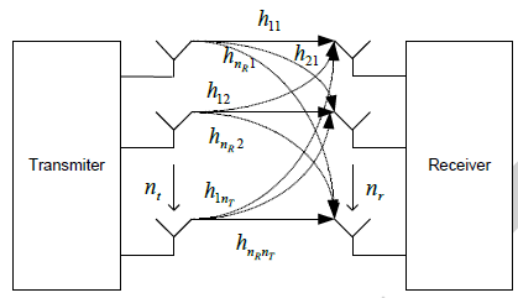

Gambar 2. alur kerja MIMO

\subsection{Multiple Access Interference}

Code Division Multiple Access (CDMA) ditunjukkan pada Gambar 3, merupakan sebuah metode mulplexing (wireless) yang menggunakan kode berbeda untuk setiap usernya. Seluruh user dapat ditransmisikan pada waktu yang bersamaan dengan menggunakan seluruh alokasi spectrum frekuensi yang ada untuk ditransmisikan [5].

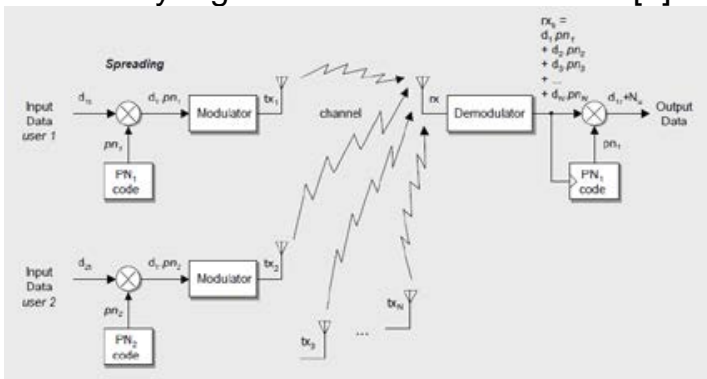

Gambar 3. dasar multiple access CDMA

Metode multiple access, mengirimkan komunikasi dari berbagai user secara bersamaan. Karena kode yang berbeda, maka pada bagian penerima data user lain akan dianggap sebagai noise [5].

\section{METODE PENELITIAN}

\subsection{Parameter Simulasi}

Parameter simulasi yang akan digunakan dalam penelitian ini dapat dilihat pada Tabel 1.

Tabel 1. Parameter simulasi sistem CDMA MIMO

\begin{tabular}{lc}
\hline \multicolumn{1}{c}{ Parameter } & Jumlah \\
\hline Jumlah User & $1,4,8,16$ user \\
Data yang dikirim & $100.000 \mathrm{bit}$
\end{tabular}




\begin{tabular}{lc} 
Spreading Factor & 16 \\
Modulasi & QPSK \\
Kode Penebar & Walsh \\
Kanal & Rayleigh Fading \\
\hline
\end{tabular}

\subsection{Pemodelan Sistem}

Pemodelan sistem yang digunakan pada penelitian ini adalah sistem CDMA yang dikombinasikan dengan MIMO STBC 2x2 pada kanal Rayleigh Fading, model ini ditunjukkan pada Gambar 4.

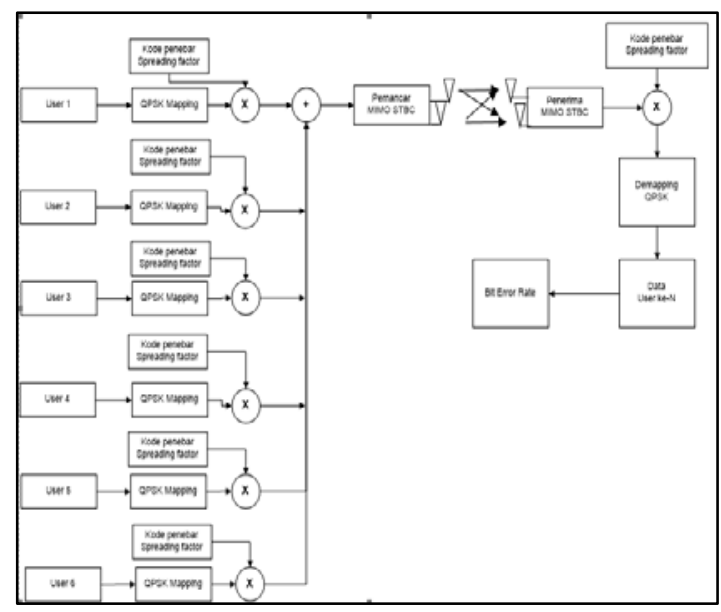

Gambar 4. Pemodelan sistem CDMA MIMO

Gambar 4 merupakan pemodelan sistem CDMA MIMO yang akan dirancang. Bagian kiri merupakan blok data dari pengirim atau user. Pada setiap user dilakukan teknik mapping QPSK (Quadrature Phase Shift Keying), yang dilanjutkan dengan teknik modulasi. Hasil modulasi setiap user akan dikirim ke pemancar CDMA. Dengan memberikan konel walsh untuk setiap user melalui saluran ini. Kemudian data akan masuk pada sistem pemancar MIMO yang mana teknik MIMO yang digunakan adalah MIMO STBC 2x2. Kemudian data akan diterima oleh penerima MIMO pada bagian penerima dan kemudian didemodulasi untuk mendapatkan data yang dikirimkan. Setelah data didapatkan, data akan dibandingkan dengan BER pada sisi pengirim dan penerima.

\subsection{Metode pengambilan data}

Analisa unjuk kerja sistem CDMA MIMO dimana dapat dibagi menjadi beberapa bagian yang dijelaskan seperti berikut ini :

1. Pada bagian mulai merupakan awal dari penelitian yang mana dilakukan persiapan persiapan untuk memulai penelitian.

2. Pemahaman literatur

3. Perancangan program simulasi Pada perancangan program simulasi dibuat pemodelan algoritma yang akan digunakan dalam penelitian sesui dengan permasalahan yang akan dibahas.

4. Pembuatan program simulasi Pada tahap ini dilakukan pembuatan program simulasi sistem menggunakan program bantu Matlab versi R2012a.

5. Uji coba sistem

Pelaksanaan uji coba program untuk mengetahui hasil dari program yang telah dibuat, serta melakukan evaluasi apabila terjadi kekurangan atau kesalahan.

6. Analisa hasil simulasi

Hasil simulasi dianalisis dengan cara melakukan :

Membuat grafik perbandingan unjuk kerja sistem CDMA MIMO dengan menggunakan kode penebar walsh serta BER sebagai acuan unjuk kerja.

7. Menarik kesimpulan berdasarkan data yang diterima dari proses simulasi dan analisa.

8. Selesai.

\section{HASIL DAN PEMBAHASAN}

4.1 Ujuk Kerja Sistem CDMA MIMO dengan Single User, 8 Users, dan 16 Users 
Hasil simulasi dari sistem CDMA MIMO dengan beberapa metode percobaan yang selanjutnya akan dianlisa akan dibahas pada sub bab ini.

Hasil simulasi sistem CDMA MIMO untuk single user ditunjukkan oleh grafik pada Gambar 5, terlihat bahwa pada saat menggunakan nilai SNR -15 dB, BER yang dihasilkan oleh sistem CDMA MIMO adalah sebesar $10^{-1}$, sedangkan pada SNR $5 \mathrm{~dB}$, BER yang dihasilkan sistem adalah sebesar $10^{-3}$.

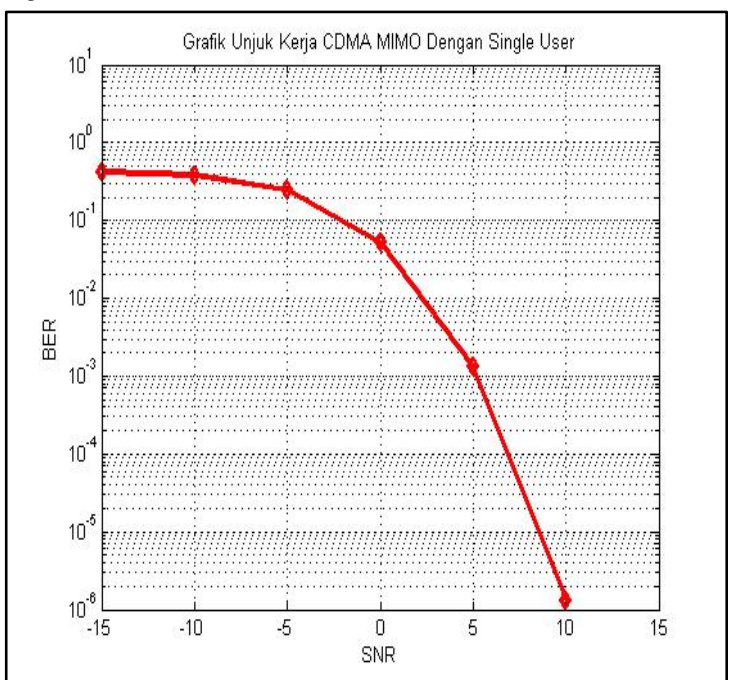

Gambar 5. Unjuk kerja sistem CDMA MIMO dengan single user

Hasil simulasi sistem CDMA MIMO untuk 8 user ditunjukkan oleh grafik pada Gambar 6. Pada saat SNR menunjukkan nilai $-15 \mathrm{~dB}, \mathrm{BER}$ yang dihasilkan oleh sistem adalah $10^{-1}$, sedangkan pada SNR $5 \mathrm{~dB}$ menunjukkan nilai BER sebesar $10^{-3}$.

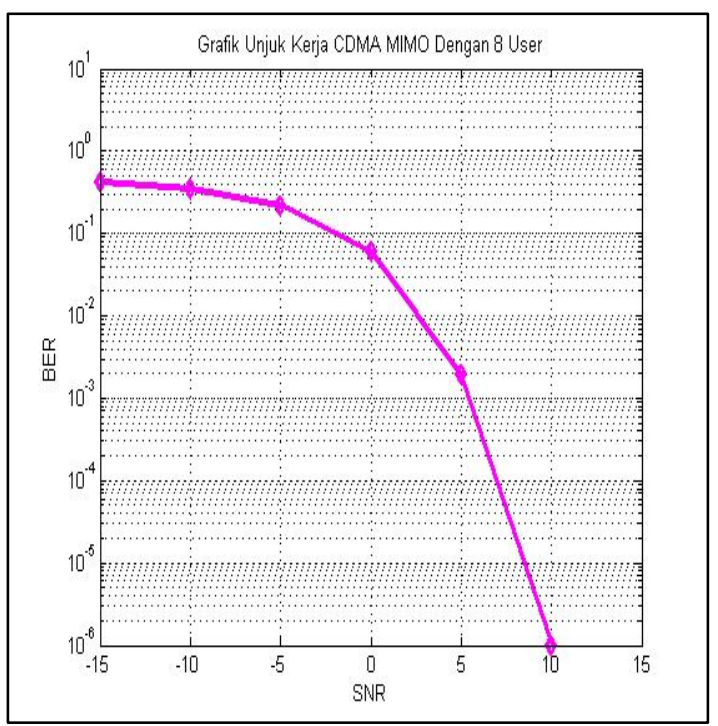

Gambar 6. Unjuk kerja sistem CDMA MIMO dengan 8 users

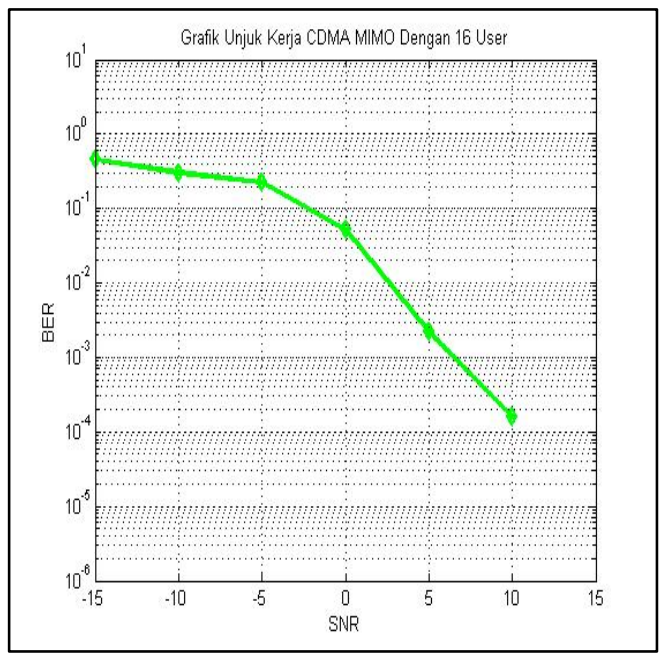

Gambar 7. Unjuk kerja sistem CDMA MIMO dengan 16 user

Simulasi sistem CDMA MIMO untuk 16 users ditunjukkan pada Gambar 7. SNR $=-15$ dB BER yang didapatkan adalah $10^{-1}$, Sedangkan SNR $=0 \mathrm{~dB}$ didapatkan BER $10^{-2}$ hingga sampai saat nilai $\mathrm{SNR}=5 \mathrm{~dB}$ didapatkan BER $10^{-3}$. 


\subsection{Unjuk Kerja CDMA MIMO dengan Pertambahan Jumlah User}

Hasil simulasi sistem CDMA MIMO untuk pertambahan user ditunjukkan pada grafik Gambar 8. Pada Gambar 8 terdapat tiga buah grafik. Grafik pertama, dengan warna merah, merepresentasikan nilai pertambahan user pada SNR sebesar $-5 \mathrm{~dB}$. Grafik kedua, warna hijau, merepresentasikan BER untuk pertambahan user dengan menggunakan SNR $0 \mathrm{~dB}$. Sedangkan grafik ketiga, warna ungu, merepresentasikan BER untuk pertambahan user dengan SNR sebesar $5 \mathrm{~dB}$. Pada Grafik warna merah memiliki nilai BER diantara $10^{-1}$, grafik warna hijau memiliki niali BER di antara $10^{-1}$ dan grafik berwarna ungu memiliki BER diantara $10^{-3}$.

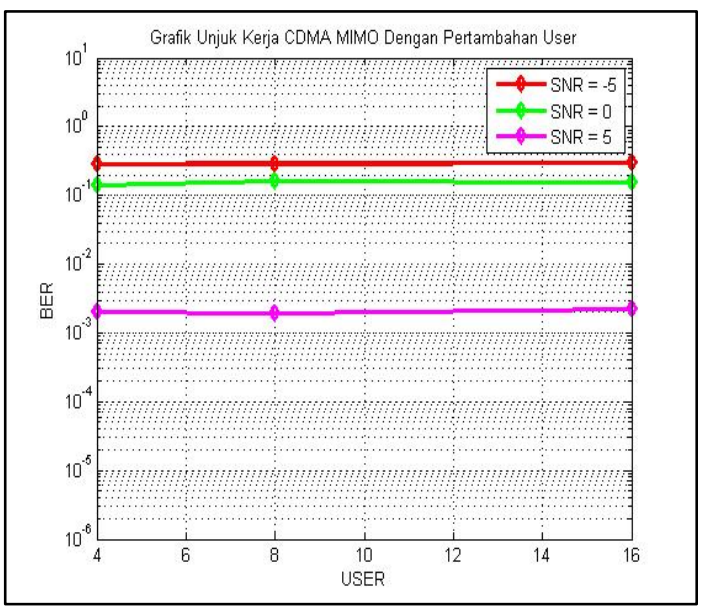

Gambar 8. Unjuk kerja sistem CDMA MIMO dengan pertambahan user

Tabel 2. Hasil perbandingan sistem CDMA MIMO dengan jumlah user yang berbeda

\begin{tabular}{|c|c|c|c|c|c|c|}
\hline \multirow{2}{*}{$\begin{array}{l}\text { SNR } \\
(\mathrm{dB})\end{array}$} & \multicolumn{3}{|c|}{$\begin{array}{l}\text { Jumlah Data Error } \\
\text { (bit) }\end{array}$} & \multicolumn{3}{|c|}{ Nilai BER (dB) } \\
\hline & $\begin{array}{c}4 \\
\text { user }\end{array}$ & $\begin{array}{c}8 \\
\text { user }\end{array}$ & $\begin{array}{l}16 \\
\text { user }\end{array}$ & $\begin{array}{c}4 \\
\text { user }\end{array}$ & $\begin{array}{c}8 \\
\text { user }\end{array}$ & $\begin{array}{c}16 \\
\text { user }\end{array}$ \\
\hline-5 & 28.3 & 28.9 & 29.52 & $2,83 \times 10^{-1}$ & $2,89 \times 10^{-1}$ & $2,952 \times 10^{-1}$ \\
\hline 0 & 14 & 16 & 15.14 & $1,4 \times 10^{-1}$ & $1,6 \times 10^{-1}$ & $1,514 \times 10^{-1}$ \\
\hline 5 & 200 & 190 & 220 & $2,0 \times 10^{-3}$ & $1,9 \times 10^{-3}$ & $2,2 \times 10^{-3}$ \\
\hline
\end{tabular}

Tabel 2 merupakan hasil perbandingan sistem CDMA MIMO dengan jumlah user yang berbeda. Dari Tabel 2 didapatkan bahwa dengan nilai SNR yang bertambah menghasilkan nilai BER yang lebih baik sehingga dapat meningkatkan kinerja sistem. Hasil ini menandakan bahwa kode Walsh dapat bekerja dengan baik pada nilai SNR sebesar $5 \mathrm{~dB}$. Meskipun terdapat perubahan jumlah user, tidak terjadi interferensi antar user karena kode Walsh merupakan kode yang orthogonal, yaitu cross correlation sama dengan nol.

\section{SIMPULAN}

Unjuk kerja sistem CDMA MIMO pada kanal Rayleigh Fading dengan menggunakan jumlah user yang berbeda memiliki nilai BER yang berbanding terbalik dengan nilai SNR yang digunakan. Pada nilai SNR -15 dB menghasilkan nilai BER $10^{-1}$, sedangkan pada nilai SNR $5 \mathrm{~dB}$ menghasilkan nilai BER $10^{-2}$. Sehingga semakin tinggi nilai SNR yang digunakan akan menghasilkan nilai BER yang lebih rendah.

Unjuk kerja sistem CDMA MIMO dengan menggunakan jumlah 4 user, 8 user, dan 16 user menghasilkan nilai yang hampir sama disetiap nilai SNR yang digunakan. Nilai BER terbaik adalah sebesar $10^{-3}$ didapatkan pada nilai SNR $5 \mathrm{~dB}$.

Unjuk kerja dari CDMA MIMO dengan pertambahan jumlah user dengan nilai SNR yang sama menghasilkan nilai yang hampir sama, yaitu untuk setiap user pada saat nilai SNR $-5 \mathrm{~dB}$ didapatkan nilai BER $=10^{-1}$. Hal ini juga juga terjadi pada nilai SNR $0 \mathrm{~dB}$ yang menghasilkan nilai $\mathrm{BER}=10^{-1}$ dan untuk SNR $5 \mathrm{~dB}$ menghasilkan BER $=10^{-3}$. Hal ini dikarenakan kode walsh bersifat orthogonal yaitu nilai dari cross correlation sama dengan nol sehingga tidak akan terjadi interferensi antar user.

\section{DAFTAR PUSTAKA}


[1] Miladiyah, Hikmah, Suwandi dan Kuswidiastuti, Devi. "Analisis Kinerja dan Kapasitas Sistem Komunikasi MIMO pada Frekuensi $60 \mathrm{GHz}$ di Lingkungan dalam Gedung". Jurnal Teknik POMITS.2014. Vol.1, No.1:1-5.

[2] Sugiono. "Unjuk Kerja Traffic Pada Sistem Telekomunikasi Selular Berbasis CDMA Area Malang". Jurnal IPTEK.2013. Vol 17 No.1

[3] Dewi, Fadhila Andam, Suryani, Titiek dan Suwadi."Implementasi dan Evaluasi Kinerja Kode Walsh Hadamard pada Code Division Multiple Access (CDMA) Menggunakan Open-Access Research Platform (WARP)".Jurnal Teknik ITS.2015. Vol 4, No 2.

[4] Awirya, Valen, Sukiswo, dan Zahra, Ajub Ajulian."Analisis Kinerja Kombinasi SIstem CDMA-OFDM dengan MIMO". TRANSMISI.2010.12(2) : 50-56.

[5] Meel, J., ir. "Spread Sprectrum (SS)". IWT HOBU Fonds, De Nayer Institute.1999. 